\title{
EPMA Characterization of Gold Associated with Different Sulfide Textures at the Monument Bay Deposit, Manitoba, Canada
}

\author{
Chunyi Hao, Juliana Casali, Zohreh Ghorbani, Hannah Cavallin, Lisa Van Loon and Neil Banerjee \\ Western University, London, Ontario, Canada
}

Introduction: The Monument Bay Project is located within the Stull Lake Greenstone Belt in the Oxford Stull Domain of the Western Superior Province in Manitoba, Canada. The Monument Bay Project is composed of three individual deposits: Twin Lakes Deposit, Mid-East Deposit, and AZ Deposit. At the Monument Bay deposit, gold is intimately associated with sulfide mineralization, particularly pyrite [1]. The growth history of pyrite can preserve changes in auriferous fluid chemistry in its distribution of trace elements across a wide range of temperature conditions. Moreover, sulfide geochemistry can be used as an effective proxy for fluid history as information recorded by different fluid events can be inferred through observation of different generations of pyrite growth [2]. In addition, quantitative $\mathrm{Au} / \mathrm{Ag}$ ratios can provide complementary information about the composition of gold grains. Understanding associations of other trace elements with gold in sulfides and the composition of gold grains can aid in differentiating mineralizing events with implications for improving exploration and geometallurgy at the Monument Bay deposit.

To analyze sulfides and microscopic gold, a combination of optical microscopy and Electron Probe MicroAnalysis (EPMA) is used. Optical microscopy provides preliminary petrology, mineralogy, and sulfide morphology in thin sections. EPMA is an in situ, non-destructive, chemical analysis of minute solid samples at small spatial scales (microns), that provides compositional information by energy-dispersive spectroscopy (EDS) and wavelength-dispersive spectroscopy (WDS). EPMA can help to confirm the results of optical petrology and morphological observations and identify microscopic gold distribution in sulfide phases. EDS element maps have also been used to analyze trace element spatial distributions in sulfide minerals, which are helpful in determining mineral paragenesis and corresponding mineralizing fluid events.

Experimental: 31 drill core samples with a gold grade of $>1 \mathrm{ppm}$ were collected from 17 different drill holes across the property. Thin sections were made from one side of the drill core and observed under plane-polarized light, cross-polarized light, and reflected light (RL) using an optical Nikon LV100POL microscope at in High-Resolution Earth and Planetary Materials Imaging Facility at Western University. Regions of interest including various sulfide morphologies and microscopic gold grains were marked and photographed under RL.

After a detailed petrographic description, thin sections were carbon-coated using a JEE-420T vacuum evaporator for EPMA at the Earth and Planetary Materials Analysis Laboratory at Western University. A JEOL JXA-8530F Hyperprobe was used for EPMA with a $20 \mathrm{keV}$ accelerating voltage. Considering the size of the selected area, the beam size was set to 1-10 $\mu \mathrm{m}$ with a dwell time of $10 \mathrm{msec}$ per spot. Point EDS analysis on gold grains provided both a spectrum and average counts of Au and Ag at each point. EPMA X-ray 2D element maps were collected on selected sulfide grains for As, Au, Ag, W, and Si by WDS, while $\mathrm{S}, \mathrm{Fe}, \mathrm{Cu}, \mathrm{Zn}, \mathrm{Pb}, \mathrm{Ni}, \mathrm{Co}, \mathrm{Al}, \mathrm{Mg}, \mathrm{Ca}, \mathrm{Ti}, \mathrm{Na}$ and $\mathrm{K}$ were collected by EDS. Based on EPMA, $\mathrm{X}$-ray element maps on sulfides, EDS point analysis was used to characterized any zoning observed for quantitative analysis of sulfide composition.

Results and Discussion: Optical microscope observation demonstrates that sulfides can be classified by the morphologies and locations within samples. Sulfides can be classified as euhedral, subhedral, and 
disseminated and appear in veins or in foliated textures. Multiple sulfides phases may occur in combinations (e.g., arsenopyrite + pyrite, pyrite + sphalerite, arsenopyrite + sphalerite, and/or arsenopyrite + galena). Some gold grains are not associated with sulfides, while some are near disseminated arsenopyrite. Gold occurs as inclusions on the edges of subhedral pyrite grains, inside subhedral sulfides, in corroded arsenopyrite, or inside chalcopyrite or galena grains. EDS point analyses show most microscopic gold is a mixture of Au+Ag with an average Au/Ag ratio of 14 (Fig.1A). From the EDS/WDS element maps, euhedral arsenopyrite grains and quartz inclusions are observed inside corroded needle-shaped pyrite grains (Fig.1B). Inclusion gold is not found inside arsenopyrite but is found along with fractures in needle pyrite. In addition, As and Mg zoning were observed in the EDS/WDS element maps of some euhedral-subhedral pyrite grains (Fig.1C). No microscopic gold has been found in zoned pyrite without fractures. There is likely evidence for 3 fluid events observed in the preliminary element maps: I . euhedral arsenopyrite formed; II. euhedral-subhedral pyrite formed; III. gold formed in fractures of pyrite. Thus, microscopy and EPMA are providing insights into sulfide formation and gold distribution on a micro-scale. This information is useful in the study of the multi-episodic fluid history and will lead to a better understanding of the mineralogical expression of gold mineralization and geometallurgy at the Monument Bay deposit.

Acknowledgment: Research described in this paper was performed at Western University. The authors thank Marc Beauchamp for sharing his knowledge and assistance with EPMA. The authors acknowledge funding from NSERC and Yamana Gold Inc.

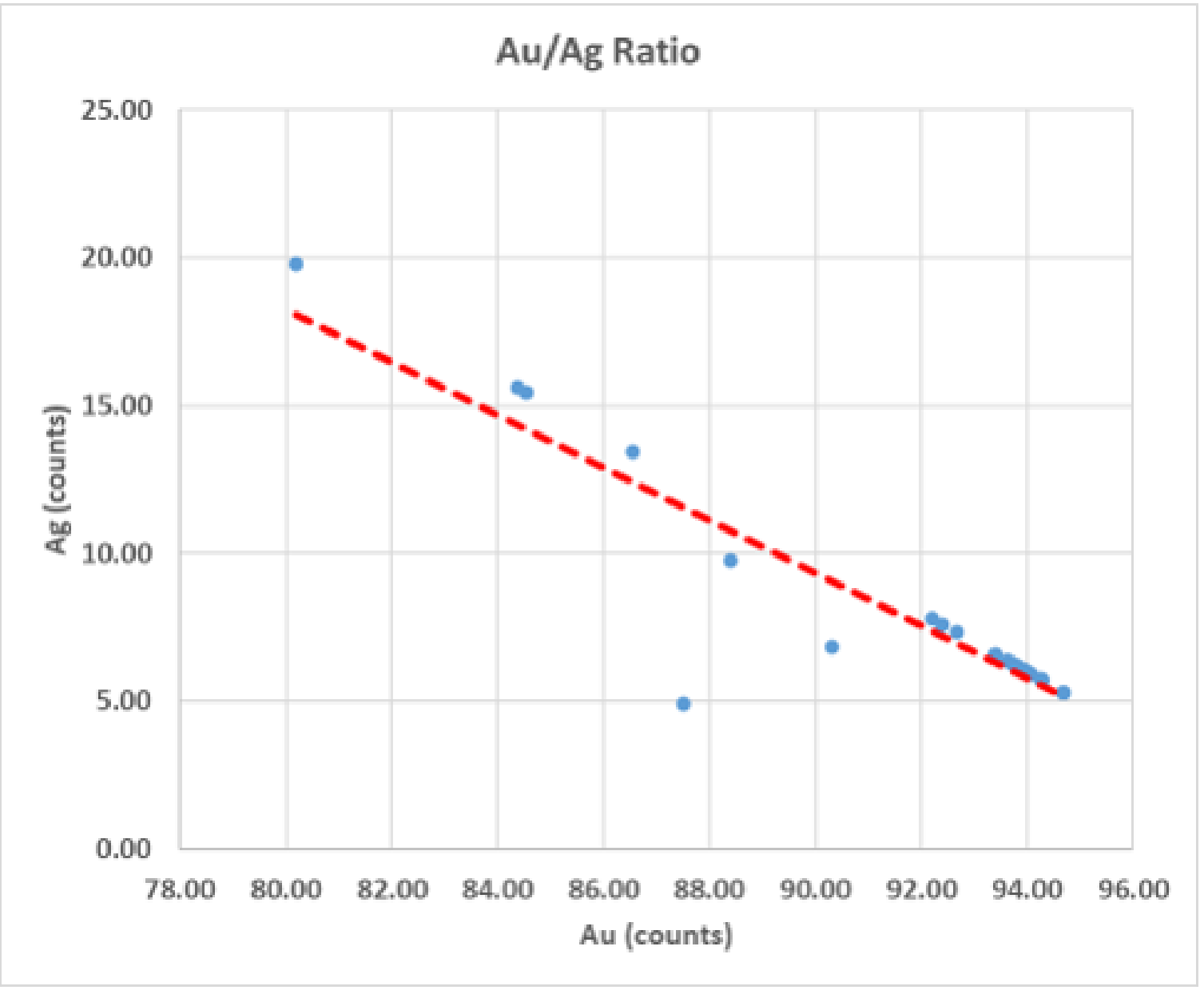

Figure 1. Au/Ag ratio of microscopic gold. 

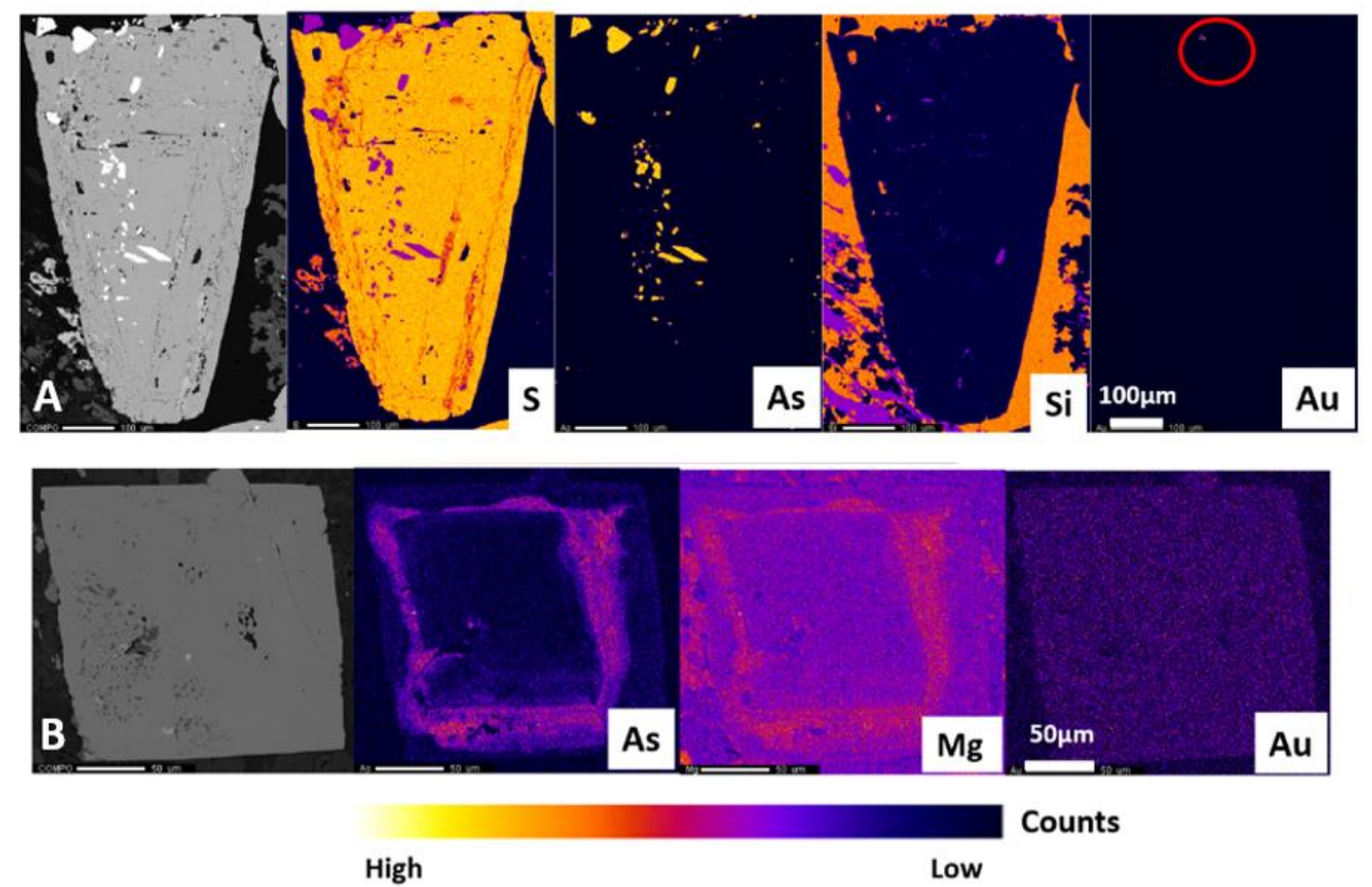

Figure 2. A\&B Back-scatted images and EDS/WDS-EPMA 2D element maps of corroded needle pyrite. and euhedral pyrite. The red circle is the high-count spot of $\mathrm{Au}$.

References

[1] H.E. Cavallin et al, Microsc. Microanal. 25 (Suppl 2, 2019) p.802

[2] J.M. Stromberg et al. Ore Geology Reviews. 104 (2019) p.603-619

[3] B. Ravel, M. Newville. J. Synchr. Rad. 12 (2005) p. 537. 